\title{
Research on the Application of Productive Agricultural Landscape in Urban Residential Area
}

\author{
Hongqiang Chen \\ Sichuan University of Arts and Science, Dazhou, China \\ Email: zjingming2019@sina.com
}

How to cite this paper: Chen, H.Q. (2021) Research on the Application of Productive Agricultural Landscape in Urban Residential Area. Open Access Library Journal, 8: e7094. https://doi.org/10.4236/oalib.1107094

Received: December 18, 2020

Accepted: January 17, 2021

Published: January 20, 2021

Copyright $\odot 2021$ by author(s) and Open Access Library Inc.

This work is licensed under the Creative Commons Attribution International License (CC BY 4.0).

http://creativecommons.org/licenses/by/4.0/

\begin{abstract}
With rapid urban construction and expansion, the space for construction is increasingly reduced. Urban productive landscape originates from living and productive labor. It is a landscape with life, culture, long-term inheritance and obvious material output. The type of productive landscape discussed in this paper is mainly based on the agricultural landscape in urban residential areas, and the agricultural products and agricultural activities are integrated into the landscape design as design elements [1]. For urban residents, there is a strong need to participate in planting activities, taste organic and healthy food, and build harmonious neighborhood relationships. The productive agricultural landscape is integrated into the design of urban residential communities [2]. Promoting the localization of urban food production, and changing the problem of formal design of residential area landscape without features play an important role in promoting the sustainable development of cities. This paper summarizes the concept of productive agricultural landscape, analyzes the feasibility and advantages of its design in residential areas, and finally puts forward some design strategies for productively agricultural landscape in urban residential areas.
\end{abstract}

\section{Subject Areas}

Sociology

\section{Keywords}

Productive Landscape, Community Garden, Landscape Design, Design Strategy

\section{Development of Productive Landscape}

China agricultural society for a long time, for thousands of years to farming 
culture affects the political, economic and cultural exhibitions, people's lifestyle and thinking mode are related, in the history of poetry, the botanical garden, calligraphy and painting are full of praise for prsoductive agricultural landscape, farming culture self-sufficiency in the mode of production, can let the modern people feel happy in the labor production, harvest production and happiness to share. Productive agricultural landscape can be traced back to the prototype of the garden "form", in the "book of songs" in Zhou Dynasty, there are most of the content described the beauty of mountains and rivers and plants, agriculture and forestry crops in the garden, the Chinese classical gardens originated of fruit tree and vegetable garden behind the house, outside the box says certain boundary or walls, square term cultivated plants or raising animals. In the West, landscape designers are mainly from farmers and ranchers. The early garden construction in the East and the West involves the production transformation of nature and the reprocessing of natural resources [3]. This is a landscape with life, culture, inheritance and material production. Thus, production is the earliest function of landscape. The rapid development of urban real estate and the improvement of people's living quality also bring a lot of problems, such as single green area, advocating evergreen trees and difficult maintenance of big lawn. In addition to the increasing concern of residents about food safety, the competition among neighbors for common sites to grow agricultural products encourages residents to privately grow edible crops such as fruits, vegetables and edible herbs in their own courtyards, balconies and roofs. The productive function of urban landscape is once again emphasized [4].

With the continuous development of productive landscape theory and practice, Andre Viljoen's book Continuous Productive Urban Landscapes aims to contribute to the ongoing debate on the shape of future cities. Continuous Productive Urban landscapes (CPULs) are put forward to integrate into existing and future vision of the city, CPULs are combined with agriculture and other landscape elements of Urban space layout, the space system with continuous contact, open space to bring a variety of characteristics. Urban agriculture based on CPULs contributes to sustainable food production and open space management and provides CPULs design strategy from the perspective of supporting urban agriculture.

For productive landscape of Chinese experts and scholars, combined with the urban question has carried on the beneficial exploration, sasaki teacher actively advocating "aesthetics" bigfoot, with practical action to change people think of the idea of landscape design in the city and interesting, the landscape as "the art of survival", for thousands of years of Chinese farming society, make the farmers with the threat and destruction of natural disasters, improving protection, irrigation, and food production skills, created a rich, harmonious "land of peach blossom garden”. In Wen Tiejun's opinion, agriculture has always been organic and has always assumed the functions of ecology and environmental protection. The destruction and pollution caused by industrialization on the outskirts of cities are only a few decades old, while agriculture has been environmentally 
friendly for thousands of years. The distance between food and people is very important. "In some countries, the local government, the scientific establishment will help you measure how close you are to getting your food. The shorter the distance, the better. The longer the distance, the less economical it is. It is anti-ecological, not environmentally friendly and not sustainable." The website of The British Farmer's Weekly advertises "local products are mile-friendly products" (John Ballingall et al., 2008). The Nativist Association encourages people to buy and consume locally grown food within 100 miles of their home to protect the world's environment with practical actions of low-carbon consumption. Under the promoting of Wen Tiejun, the existence of a combined with urban people farm in the city, promote consumer cooperatives, choose suitable production base, with the local traditional mode of production, plant production is most suitable for the local agricultural products, the production of ecological field, public health products directly to the table, reduce the circulation of agricultural products, provide urban consumers health and true information for agricultural products.

The current urban construction entered a new stage of development, the city residents to greening quality and the demand of the village, a series of incidents of food safety and agricultural production and ecological circulation way gradually attracted people's attention, agricultural production can also be used as a part of city landscape construction, the application of the "productive" typical characteristics of landscape in urban residential area, so as to realize the natural value, the combination of safety value and cultural value.

\section{Function of Productive Agricultural Landscape}

As a new urban landscape design strategy, productive landscape has become an important part of urban sustainable development. It has many functions such as nature, safety and culture in the landscape design of urban residential areas.

\subsection{Better Integrate Urban Landscape into Nature}

As human beings yearn for nature, cities need to be green. More and more cities take livable cities as the development model and integrate the productive agricultural landscape into cities, which reflects the harmonious relationship between human and nature and is a sustainable model. It is helpful to prevent the problems of insufficient supply of ecological products and overload of carrying capacity of resources and environment in the process of urbanization, and to realize the grand goal of building a moderately prosperous society in all respects. The introduction of productive agricultural landscape, especially in urban residential areas, can feel the process of crop planting in spring and harvest in autumn, making people feel that people are a part of nature. Most agricultural landscapes choose plant species from the native land. Native plants have great advantages in adapting to the local environment, forming a large number of biological communities in a very short time, providing food and habitat for insects, birds and other small animals, which is conducive to the repair of urban 
ecological damage and the protection of biodiversity. Into such an environment, people can open the door see green, push the window scene, mountain, water, forest, farm, lake and crops nature fusion, is a unique green feast, but also a spiritual dialogue between human and nature, to enlighten people and combines the productive agricultural landscape and life, feel the natural beauty and the beauty of pastoral, common experience ecological significance of the harmonious coexistence between man and nature and wisdom.

\subsection{Effectively Promote Food Security and Ecological Security}

It is predicted that by 2050 , nearly 70 percent of the world's population will be living in cities. Urban agriculture is critical to providing food for urban dwellers and could produce as much as 180 million tons of grain a year, or about 10 percent of the global production of beans and vegetables, according to a 2018 study published in the journal Earth's Future. Food security and transportation issues are a growing concern, as city dwellers consider where their food comes from, the disruption of their supplies and how to reduce that disruption for their own health. For example, when novel Coronavirus suddenly appeared in some cities, the panic purchase caused the supermarket shelves to be swept away, the food transportation was affected, and the logistics was interrupted, the vulnerability of big cities appeared. These factors are pushing more city dwellers to grow fruits and vegetables in their home communities, providing a potentially lasting boost to urban agriculture. At present, Liu's team has helped to build more than 60 community gardens in different types of communities in 12 districts of Shanghai. With the strategy of design, construction, management and education, residents have become the masters of green space. The small and micro garden at home, from design and construction to maintenance and management, can be completed by residents' collaborative efforts. We have green Onions, Chinese cabbage, cabbages and so on. If you need any other varieties, residents can give you suggestions. We will make adjustments according to your needs. When the vegetables are ripe, you can help yourself to them. When the harvest season comes, we will also deliver these vegetables to the families in the community who have difficulties in living, so that they can also feel the love from the community and the neighbors. To urban residents, "harvest" and "neighborhood feast" seem to be some local memories full of human interest but gradually blurred. With the coming of the harvest season, residents jointly organized a harvest neighborhood feast to regain their local memories.

Into productive agriculture in city residential area landscape, can be in circulation shortening the distance between people and food, consumer and producer, helps to build trust, to share a good neighborhood relationship, advocate "in the local food in the quarter,", the organic fusion of agricultural and urban life, farmers construction of urban and rural residents [5]. To improve the way urban land is used, people participate in agricultural cultivation, improve food security and nutrition, and reduce the pressure on food transport, increase biodiversity, reduce the impact of climate change, ensure ecological security and other issues. 


\subsection{Improve the Sense of Participation and Identity of Urban Residents}

With the acceleration of the urbanization process, the greening intensity of urban landscape design has been continuously increased, and the violation of green has been dismantled among cities, and residential communities have become the daily living places of urban residents [6], residential developers pay more attention to the visual landscape, to better attract the eye, constantly introduce rare trees, widely planted lawns, fountain square, a school of lively garden landscape, its environment and people's mind the ideal wonderland of peach garden increasingly far away. Such landscape participation performance is poor. Before large-scale planting of sod, people could chat and entertain themselves in the shade of the community, but the lawn planted everywhere shuts people out and can only be viewed, not integrated into the green [7]. After being integrated into the productive agricultural landscape, residents can have the opportunity to grow agricultural products and create a relaxing and cheerful labor experience. In the process of people's participation, residents become passive appreciating to active participation, which increases the joy of labor. During the whole life cycle of crop planting, plants experience the growth process from germination to seedling to tiller to ear to fruiting. From time to time, they would like to take a closer look at the actual growth appearance of crops and the refreshing feeling of harvest. People get closer to nature, mobilize residents to actively participate in the construction of landscape, make it more convenient to gather and interact, and meet each other's needs through productive agricultural landscape.

Residents through their collaboration to participate in, to get food supply personal or family to eat, for the school or community, through community support agriculture direct sales of agricultural products, can also be for the urban low-income groups to supplement source of food, get social recognition, can also play a resident expertise, by introducing the productive agricultural landscape and concept, such as Spring Festival, the harvest festival held on a regular basis, by publishing to grow their own publications and practice courses, more widely mobilize citizens, social groups to participate in, make the agricultural production in residential area, improve the economic benefit, ecological benefit, social benefit is remarkable, let the agricultural culture. The participants had a sense of identity.

\section{Design Strategies for Productive Agricultural Landscape in Urban Residential Areas}

Rich green space in residential area and residential building space structure such as balcony, roof, lead to the diversity of productive agricultural landscape implementation field in realistic applications should be according to the target audience demand, technology, and an organic combination of crop varieties, positioning function of the city, for the productive agricultural landscape presenta- 
tion layout and production purpose effectively and build the safe, efficient and sustainable urban productive agricultural landscape.

\subsection{Extensive Introduction of Consumer Participation}

The productive agricultural landscape has been carefully designed to meet the residents' long-standing desire to strengthen land connections and help to unite the residents. Based on the experience of Europe, the United States, the rise of China's middle class is inevitable, they have the economic ability, safety is their common needs, they are eager to return to the wild, participation and management process of farming, contribute to the safety of the agricultural productive landscape output, through the "participatory certification", consumers to grow their own agricultural products, without any organic certification, no one will doubt its safety, residents here as a producer, naturally formed a kind of supervision, to be able to build agricultural production and consumer trust. Through a community of mutual widely naturalized in agriculture, farmers market, sightseeing agriculture, consumer involvement, village owner can be tube in the owners' committee and with the help of the small green ecological renovation, composed of a single grass, trees, in the past, to switch to fruits and vegetables, form citizen organic co-op, who to agricultural cooperatives, who enjoy the rebates and rights and interests of the many.

\subsection{Create a Multi-Level Landscape Type}

In addition to implementing productive agricultural landscape transformation in the land area of residential areas, we should seek for a way out of three-dimensional green space, turn the roofs of urban residents into vegetable gardens and balconies of residential buildings into planting landscape, and integrate relevant technologies of three-dimensional green construction of urban residential buildings into a new urban agricultural culture industry. Multi-level development at the top of the building space, in the idle to develop agriculture in the roof, not only cool and heat insulation effect is good, but can purify air, improve local microclimate, also can enrich the urban pitching landscape, less bare concrete, can compensate for building green ground, greatly improving the city's green coverage rate. With a rooftop garden of about 30 square meters, a family of three can afford to eat their own food every year during the vegetable season. "Kodo Farm Model" founded by Song Zhiyuan in Chengdu, aims to turn the outer walls of city buildings into layers of vegetable gardens. Open the door of the balcony, you can see the green organic fruits and vegetables at first sight. In the Kodo farm model, the racks are not simply stacked, but layered and divided into species. For example, chickens can be raised under the vegetable rack on the first floor, pond fish can be dug in the open space in front of the building, vegetable leaves can be fed to chickens, and chicken manure can be used to raise fish, with no recycling emissions and no public hazard in the whole process. Not only can you enjoy fresh green vegetables, but you can also enjoy high-quality chicken and fish. 
In addition, the area that housetop farm garden can rest for him, friend, exchange, admire, still be the recreational place of old person, child and popular science class, build gave relaxed and harmonious environment, decorated resident community environment not only, more added dimensional colour, let a person heart got loosen. It is helpful for children to find out more secrets of growth in the process of planting, effectively cultivate children's creativity and discovery power, in addition to experiencing life, but also let them know the hard-won food.

\subsection{Expand the Landscape Functions of Urban Residential Areas}

Traditional residential landscape takes sightseeing as its main purpose, while productive agricultural landscape pays more attention to people's active participation and experience in addition to its unique farming and output functions. Farmland, orchard, vegetable garden to harvest, in the process of plant growth, can also be developed for urban farming culture, folk custom performance, children learn to provide places, such as expanding the function of the urban residential area landscape, into the educational agriculture, experiential agriculture, let the children to participate in, to understand the ecological organic agriculture, have the effect of popular science education; Ecological restaurants can be set up in cities to eat 100 percent of farm products, so that customers can taste and consume seasonal food instead of food that is transported over a long distance and has multiple freshness. Every year, a planting festival and a harvest festival are held on the campus of Shenyang Jianzhu University. Agricultural production has become a wonderful scene for college students and nearby middle school students. The harvested grain is packed in bags of "golden rice", which is not only sold in the school cafeteria, but also given to visitors as a souvenir. Now "golden rice" has become the school's status symbol. Based on residential agricultural parks, we will explore ways to build an agricultural industry chain, build a new urban pastoral front integrating planting, sightseeing and education, provide the nearest place for consumption, tourism and natural experience, and constantly improve the economic and social efficiency of productive agricultural landscape.

\subsection{Urban Ecological Restoration}

Climate change and the loss of farmland caused by human activities will bring more floods, rainstorms, droughts, diseases, extinctions of plants and animals, and threats to human existence. Productive agricultural landscape in the city, through the design gimmick of the adjust measures to local conditions, the maximum use of scientific planting technology, the implementation of production and supply of food at the same time, play for the sustainable development of urban ecological restoration and the farming area, the utilization of rainwater collection and microbial fermentation technology, improve the ability of self purification of the city, the use of natural plant nutrient solution of production and the method of some physical prevention and control plant diseases and in- 
sect pests, and through crop rotation, intercropping, diversification, lie fallow, pursue overall ecosystem diversity of the farm, as far as possible to reduce damage to the ecological environment.

\section{Conclusions}

Based on the design of the application of productive agricultural landscape in urban residential areas, this paper lacks the corresponding systematic analysis, lacks the targeted research on the implementation site, lacks the detailed research on the technical guarantee, policy research and community governance of productive agricultural landscape, etc., and should add the systematic research of relevant disciplines in the follow-up.

At present, urbanization has entered the stage of rapid development, there are many problems in the landscape design of urban residential areas, and residents are also facing new demands. Productive agricultural landscape is applied to the practical design of urban residential area, will be a good change way, and with material production and improve living happiness "productive landscape", the inhabitants from "passive recipients" to "create", think in everybody's life and meet the pursuit of rural life, urban residents to promote to realize the sustainable development of cities.

\section{Conflicts of Interest}

The author declares no conflicts of interest regarding the publication of this paper.

\section{References}

[1] Song, Y. (2011) Research on Productive Landscape Practice in China's Rapid Urbanization Stage. Tianjin University, Tianjin.

[2] Hou, J. (2017) Feasibility Analysis and Design Research of Productive Landscape in Urban Residential Area. Xi'an University of Architecture and Technology, Xi'an.

[3] Hu, R.Y. (2017) Research on Low-Cost Rural Landscape Renovation Planning: A Case Study of Dadou Mountain Village in Tai'an. Shandong Agricultural University, Tai'an.

[4] Zhang, J. and Wu, L. (2014) Urban Productive Landscape and Its Practical Methods. Art Review, 7, 145-148.

[5] Zhao, C. (2017) Development Dilemma and Countermeasures of Beijing Little Donkey Citizen Farm Park. Journal of Beijing Agricultural Vocational College, 3, 10-16.

[6] Chen, S.X. (2012) Discussion on Urban Landscape Design. Urban Construction Theory Research (Electronic Version), 95, 104.

[7] Guo, X.D. (2006) Garden Landscape Design Miscellany. Vol. 3, China Folk Art Press, Beijing. 